\title{
Bosentan therapy for portopulmonary hypertension
}

\author{
M.M. Hoeper*, M. Halank", C. Marx", G. Hoeffken\#, H.J. Seyfarth`, J. Schauer", \\ J. Niedermeyer* and J. Winkler"
}

\begin{abstract}
The dual endothelin receptor antagonist bosentan has been approved in several countries for pulmonary arterial hypertension, and patients with portopulmonary hypertension (PPHTN) have not specifically been excluded. However, no data have been published on the efficacy and safety of bosentan in this patient population. Here, the first clinical experiences with bosentan in patients with Child A cirrhosis and severe PPHTN are reported.

In total, 11 consecutive patients with cirrhosis and severe PPHTN in New York Heart Association Functional Classes III and IV were treated for $>1 \mathrm{yr}$ with bosentan.

After $1 \mathrm{yr}$ of treatment with bosentan, all patients showed improved symptoms and exercise capacity. The 6-min walking distance increased from $310 \pm 102 \mathrm{~m}$ at baseline to $388 \pm 81 \mathrm{~m}$ at $1 \mathrm{yr}$. Cardiopulmonary exercise testing disclosed a significant increase in peak oxygen uptake, from $12.6 \pm 3.5$ to $16.6 \pm 2.8 \mathrm{~mL} \cdot \mathrm{min}^{-1} \cdot \mathrm{kg}^{-1}$. Pulmonary vascular resistance fell from $944 \pm 519$ to $635 \pm 321$ dynes $\cdot s \cdot L^{-1}$. The medication was well tolerated by all patients, and there was no evidence of drug-related liver injury.

In conclusion, bosentan proved to be efficacious and safe in a small number of patients with portopulmonary hypertension.
\end{abstract}

KEYWORDS: Cirrhosis, endothelin receptor antagonists, secondary pulmonary hypertension

$\mathbf{T}$ he development of pulmonary arterial hypertension $(\mathrm{PAH})$ in patients with portal hypertension is referred to as portopulmonary hypertension (PPHTN) [1]. This complication predominantly affects patients with cirrhosis of various aetiologies accompanied by portal hypertension, but may also occur in noncirrhotic portal hypertension. Thus, it appears that portal hypertension rather than liver dysfunction triggers the occurrence of pulmonary hypertension [2].

The incidence of PPHTN varies widely in the medical literature. An autopsy study found vascular changes compatible with severe pulmonary hypertension in $0.7 \%$ of patients with cirrhosis [3], whereas most clinical series have described much higher incidences, ranging $2-16 \%$ [1, 4-9]. These differences may be the result of different study populations, but also of different diagnostic criteria. In many cases, patients with cirrhosis develop only mild-tomoderate elevation of pulmonary vascular pressure in the presence of a high cardiac output and mildly elevated pulmonary vascular resistance. These patients usually show no symptoms related to pulmonary hypertension and specific treatment may not be required [2]. However, for unknown reasons, some patients develop progressively symptomatic pulmonary hypertension with right heart dysfunction. In these patients, the prognosis is poor with 1-yr mortality rates ranging $24-60 \%[7,10]$.

The only specific treatment available for PPHTN has been intravenous epoprostenol. There are no controlled trials of epoprostenol in this patient population, but several case series suggest a positive effect on exercise capacity and haemodynamics [11-15], although it has been questioned whether epoprostenol improves survival in PPHTN [16].

The dual endothelin receptor antagonist bosentan is efficacious in patients with idiopathic PAH and PAH related to connective tissue disease [17, 18]. Elevation of hepatic aminotransferase levels is a common phenomenon in patients treated with bosentan, occurring in $\sim 10 \%$ of patients receiving $125 \mathrm{mg}$ twice daily [18]. Owing to concerns about potential liver toxicity, patients with PPHTN have been excluded from clinical studies with bosentan, and physicians have been reluctant to prescribe the drug in patients with cirrhosis. However, the US Food and Drug Administration and the European Agency for the Evaluation of Medicinal Products have approved bosentan for
AFFILIATIONS

*Dept of Respiratory Medicine, Hanover Medical School, Hanover, \#Dept of Respiratory Medicine, Carl Gustav Carus University of Dresden, Dresden, and

'Dept of Respiratory Medicine, University of Leipzig, Leipzig, Germany.

CORRESPONDENCE

M.M. Hoeper

Dept of Respiratory Medicine

Hannover Medical School

30623 Hannover

Germany

Fax: 495115328536

E-mail: hoeper.marius@mh-

hannover.de

Received:

July 052004

Accepted after revision:

October 152004

SUPPORT STATEMENT

M.M. Hoeper has received speaker's honoraria and served as an advisory board member for Actelion (Allschwil, Switzerland), the manufacturer of bosentan. J. Winkler and M. Halank have received speaker's honoraria from Actelion. The present study was not funded by Actelion or any other third party.

European Respiratory Journal Print ISSN 0903-1936 Online ISSN 1399-3003 
all forms of PAH, not specifically excluding PPHTN, as long as liver function is stable.

The present article reports the first long-term clinical experiences with bosentan in patients with cirrhosis and severe PPHTN.

\section{METHODS}

Clinical data were retrospectively collected from all patients who were referred with newly diagnosed severe PPHTN (New York Heart Association (NYHA) Functional Class III or IV; mean pulmonary arterial pressure $\left.\left(\bar{P}_{\text {pa }}\right)>40 \mathrm{mmHg}\right)$, between January 2001 and February 2003, to three German university hospitals (Hanover Medical School, Hanover; Carl Gustav Carus University of Dresden, Dresden; and University Hospital Leipzig, Leipzig). At this time, all patients with PPHTN and Child A cirrhosis were treated with bosentan, since no other drug has gained approval for the treatment of this condition in Germany. All patients were carefully informed about the lack of clinical experience with bosentan in PPHTN and safety concerns about potential liver toxicity, and gave written informed consent. There was no formal study protocol, and the patients were treated at the discretion of their local physicians. This approach was approved by the institutional review boards of all the participating centres.

Bosentan was started at a dose of $62.5 \mathrm{mg}$ twice daily in all patients, and the dose was increased to $125 \mathrm{mg}$ twice daily after 4-8 weeks based on clinical judgement and tolerability. Liver enzyme, including alanine aminotransferase and aspartate aminotransferase, and bilirubin levels were monitored twice monthly during the first 3 months and monthly thereafter. All patients were seen in the outpatient clinics of the university hospitals at 3-monthly intervals for a thorough clinical investigation, including assessment of NYHA Functional Class, 6-min walking distance (6MWD), and pulmonary and liver function. Right heart catheter examinations were performed in all patients within 6 months before bosentan treatment was started and after $1 \mathrm{yr}$ of treatment. Cardiac output was measured by thermodilution in triplicate and averaged. Samples for arterial and mixed venous blood gas analysis were obtained during heart catheterisation without supplemental oxygen. The alveolar-arterial oxygen tension difference $\left(\mathrm{PAa}, \mathrm{O}_{2}\right)$ was calculated by subtracting arterial oxygen tension $\left(\mathrm{Pa}_{2} \mathrm{O}_{2}\right)$ from alveolar oxygen tension $\left(\mathrm{PA}, \mathrm{O}_{2}\right)$ (with $P A, \mathrm{O}_{2}=150$-arterial carbon dioxide tension $\left.\left(\mathrm{Pa}_{\mathrm{a}} \mathrm{CO}_{2}\right) / 0.8\right)$. Regular cardiopulmonary exercise testing, following a standardised protocol on a cycle ergometer [19], was part of the routine programme in two centres.

\section{Statistics}

All data are presented as mean \pm SD. A paired $t$-test (two-sided) was used to compare variables at baseline and after $1 \mathrm{yr}$ of treatment. A p-value of $<0.05$ was considered significant.

\section{RESULTS}

Between January 2001 and January 2003, bosentan treatment was initiated in 11 consecutive patients with PPHTN (at Hanover Medical School $(n=4)$, University Hospital Leipzig $(n=4)$ and Carl Gustav Carus University of Dresden $(n=3))$, who presented with stable liver function (Child-Pugh class A) but severe functional limitation due to pulmonary hypertension (NYHA Functional Class III or IV). The final dose of bosentan was $125 \mathrm{mg}$ b.i.d. in six patients and $62.5 \mathrm{mg}$ b.i.d.in the remaining five. The demographics and baseline characteristics of these patients are shown in table 1. The majority of the patients suffered from alcoholic liver disease, but all such patients had abandoned alcohol consumption $\geqslant 6$ months (median interval 38 months) before bosentan was introduced. The diagnosis of cirrhosis and portal hypertension was confirmed by expert hepatologists in all patients, and all patients had a history of one or more complications of portal hypertension, such as ascites, oesophagogastric varices or

TABLE 1 Demographics and baseline characteristics of patients with cirrhosis and severe portopulmonary hypertension

\begin{tabular}{|c|c|c|c|c|c|c|c|c|c|c|}
\hline $\begin{array}{l}\text { Patient } \\
\text { No. }\end{array}$ & Sex & Age yrs & Aetiology & $\begin{array}{l}\text { Liver } \\
\text { biopsy }\end{array}$ & $\begin{array}{c}\text { Previous } \\
\text { complications } \mathbf{s}^{\#}\end{array}$ & \multicolumn{2}{|c|}{ Smoking } & VC \% pred & FEV $_{1} / \mathrm{VC}$ & $D \mathrm{~L}, \mathrm{CO} \%$ pred \\
\hline
\end{tabular}

\begin{tabular}{|c|c|c|c|c|c|c|c|c|c|c|}
\hline 1 & $M$ & 51 & Alcohol abuse & No & $V, S$ & CS & 10 & 112 & 71 & 56 \\
\hline 2 & $M$ & 66 & Cryptogenic & Yes & $A$ & NS & 0 & 81 & 76 & 40 \\
\hline 3 & $M$ & 42 & Alcohol abuse & Yes & $V, S$ & CS & 25 & 75 & 75 & 46 \\
\hline 4 & $\mathrm{~F}$ & 48 & Hepatitis C & Yes & $\mathrm{V}, \mathrm{S}$ & CS & 20 & 68 & 65 & 51 \\
\hline 5 & M & 51 & Alcohol abuse & No & V, S, A & CS & 20 & 90 & 75 & 70 \\
\hline 6 & $\mathrm{~F}$ & 62 & Alcohol abuse & Yes & $\mathrm{V}, \mathrm{VB}, \mathrm{S}, \mathrm{A}$ & Ex & 10 & 91 & 58 & 38 \\
\hline 7 & $\mathrm{~F}$ & 55 & Cryptogenic & Yes & V, VB, S & NS & 0 & 111 & 57 & 41 \\
\hline 8 & $\mathrm{~F}$ & 37 & Biliary atresia & No & V, S & NS & 0 & 101 & 79 & 66 \\
\hline 9 & M & 51 & Alcohol abuse & No & $A, S$ & Ex & 7 & 87 & 85 & 75 \\
\hline 10 & $\mathrm{~F}$ & 41 & Alcohol abuse & No & $\mathrm{V}, \mathrm{A}$ & CS & 20 & 89 & 77 & 57 \\
\hline $11^{\circ}$ & $\mathrm{F}$ & 63 & Alcohol abuse & No & $V, A, S$ & NS & 0 & 58 & 60 & 50 \\
\hline
\end{tabular}

VC: vital capacity; FEV1: forced expiratory volume in one second; $D L, C O$ : carbon monoxide diffusing capacity of the lung; M: male; F: female; V: oesophagogastric varices; S: splenomegaly; A: ascites; VB: variceal bleeding; CS: current smoker; NS: nonsmoker; Ex: ex-smoker; \% pred: percentage of the predicted value. ${ }^{\#}$ : of portal hypertension; ": patient suffered from cirrhosis, pulmonary hypertension and a sinus venous defect with right-to-left shunting 
hypersplenism (table 1). Preliminary data from one patient (No. 2) have already been published as a case report [20].

At baseline, pulmonary function testing revealed mild-tomoderate impairment of $\mathrm{DL}, \mathrm{CO}$ in the majority of the patients as five patients had $D \mathrm{~L}, \mathrm{CO}$ of $\leqslant 50 \%$ of the predicted value and four of $50-70 \%$ pred. In addition, mild airflow obstruction, with a forced expiratory volume in one second/vital capacity ratio of $<70 \%$, was present in four patients (table 1 ). The results of pulmonary function testing remained virtually unchanged after $1 \mathrm{yr}$ of bosentan treatment (data not shown).

\section{Outcome, functional classification and exercise capacity}

No patient underwent transplantation or died during the observation period. All 11 patients reported subjective improvement in exercise capacity after initiation of bosentan treatment, and six patients improved by one functional class. The 6MWD increased from $310 \pm 102 \mathrm{~m}$ at baseline to $388 \pm 81 \mathrm{~m}$ after $1 \mathrm{yr}(\mathrm{p}=0.0004)$. Data from cardiopulmonary exercise testing were available from seven patients and revealed a significant increase in peak oxygen uptake, from $12.6 \pm 3.5$ to $16.6 \pm 2.8 \mathrm{~mL} \cdot \mathrm{min}^{-1} \cdot \mathrm{kg}^{-1}(\mathrm{p}=0.01)$, as well as an increase in oxygen pulse, from $6.7 \pm 1.2$ to $9.3 \pm 2.1 \mathrm{~mL}$ $(p=0.01)$. Ventilatory efficiency (minute ventilation/carbon dioxide production) at the anaerobic threshold showed a tendency to decrease from $57.7 \pm 22.1$ to $46.9 \pm 11.7$, but this change was not significant $(p=0.31)$. The individual NYHA classification at baseline and after $1 \mathrm{yr}$ of treatment together with the change in 6MWD and variables obtained from cardiopulmonary exercise testing are shown in table 2.

\section{Haemodynamic studies and blood gas analyses}

The individual results of the haemodynamic studies are shown in table 3. Treatment with bosentan caused a nonsignificant fall in $\bar{P}_{\text {pa from }} 53 \pm 9$ to $48 \pm 14 \mathrm{mmHg}(p=0.23)$. Cardiac output rose, from $4.6 \pm 1.8$ to $5.7 \pm 1.6 \mathrm{~L} \cdot \mathrm{min}^{-1}$ (cardiac index $2.5 \pm 1.0$ and $3.1 \pm 0.8 \mathrm{~L} \cdot \mathrm{min}^{-1} \cdot \mathrm{m}^{-2}$, respectively; $\left.\mathrm{p}=0.02\right)$,

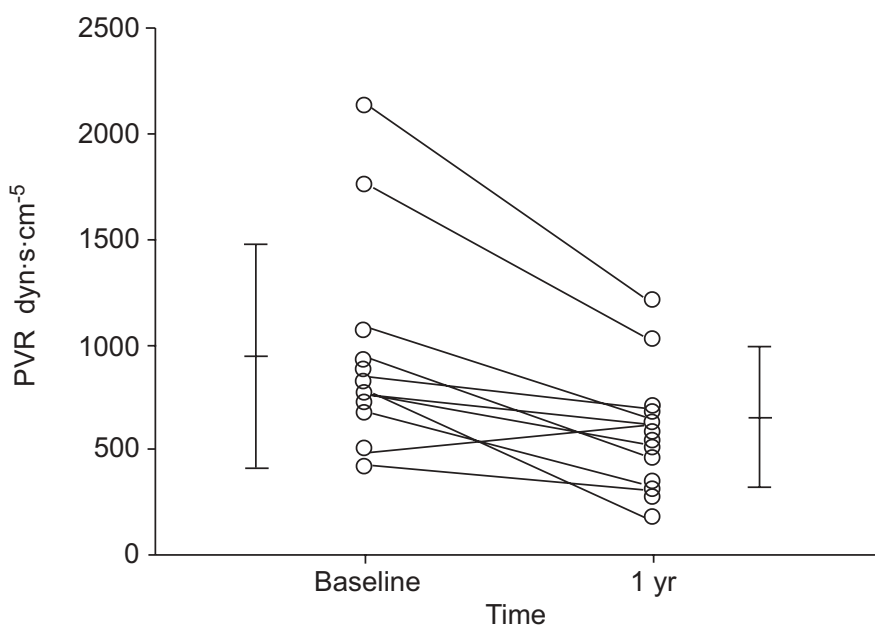

FIGURE 1. Impact of bosentan treatment on pulmonary vascular resistance (PVR) in 11 patients with portopulmonary hypertension. Separate points represent individual patients; horizontal and vertical bars represent mean $\pm \mathrm{SD}$

resulting in a significant fall in pulmonary vascular resistance, from $944 \pm 519$ to $635 \pm 321$ dynes $\cdot \mathrm{s} \cdot \mathrm{cm}^{-5}(\mathrm{p}=0.007$; fig. 1$)$. The increase in cardiac output was due to a rise in stroke volume from $57 \pm 20$ to $70 \pm 23 \mathrm{~mL}(p=0.01)$, whereas the cardiac frequency remained unchanged (data not shown). Mixed venous oxygen saturation was $60 \pm 9 \%$ at baseline and $63 \pm 11 \%$ at $1 \mathrm{yr}(\mathrm{p}=0.4)$. The right atrial pressure fell slightly, from $9 \pm 6$ to $7 \pm 7 \mathrm{mmHg}$, a change that was also nonsignificant $(p=0.35)$. The mean systemic artery pressure dropped from $91 \pm 9$ to $83 \pm 14 \mathrm{mmHg}(\mathrm{p}=0.09)$.

As shown in table 3, blood gas analyses disclosed a significant worsening of arterial oxygenation. The $\mathrm{Pa}_{1} \mathrm{O}_{2}$ fell from $8.6 \pm$ $1.7 \mathrm{kPa}(65 \pm 13$ Torr) at baseline to $7.7 \pm 1.5 \mathrm{kPa}(58 \pm 11$ Torr $)$ after $1 \mathrm{yr}(\mathrm{p}=0.006) ; \mathrm{Pa}_{1} \mathrm{CO}_{2}$ was unchanged; and the $\mathrm{PAa}, \mathrm{O}_{2}$;

\begin{tabular}{|c|c|c|c|c|c|c|c|c|}
\hline \multirow{2}{*}{$\begin{array}{l}\text { Patient } \\
\text { No. }\end{array}$} & \multicolumn{2}{|c|}{ NYHAFC } & \multicolumn{2}{|c|}{ 6MWD m } & \multicolumn{2}{|c|}{$V^{\prime} \mathrm{O}_{2}, \max \mathrm{mL} \cdot \mathrm{min}^{-1} \cdot \mathrm{kg}^{-1}$} & \multicolumn{2}{|c|}{$V^{\prime} \mathrm{O}_{2} / f_{c} \mathrm{~mL}$} \\
\hline & Baseline & $1 \mathrm{yr}$ & Baseline & $1 \mathrm{yr}$ & Baseline & $1 \mathrm{yr}$ & Baseline & $1 \mathrm{yr}$ \\
\hline 1 & III & $\|$ & 400 & 450 & 17.1 & 22.9 & 8.6 & 12.7 \\
\hline 2 & III & III & 360 & 370 & 14.1 & 14.7 & 7.5 & 8.7 \\
\hline 3 & III & III & 250 & 360 & 8.3 & 15.8 & 6.1 & 11.4 \\
\hline 4 & III & $\|$ & 358 & 396 & 12.7 & 15.6 & 6.3 & 7.4 \\
\hline 5 & III & $\|$ & 264 & 455 & 7.5 & 15.7 & 5.3 & 9.7 \\
\hline 6 & III & $\|$ & 327 & 407 & 13.2 & 15.5 & 7.5 & 8.2 \\
\hline 7 & III & III & 280 & 375 & 15.0 & 16.1 & 5.9 & 7.2 \\
\hline 8 & III & III & 392 & 448 & NA & NA & NA & NA \\
\hline 9 & III & III & 476 & 504 & NA & NA & NA & NA \\
\hline 10 & III & III & 168 & 280 & NA & NA & NA & NA \\
\hline 11 & IV & III & 140 & 224 & NA & NA & NA & NA \\
\hline Mean \pm SD & & & $310 \pm 102$ & $388 \pm 81$ & $12.6 \pm 3.5$ & $16.6 \pm 2.8$ & $6.7 \pm 1.2$ & $9.3 \pm 2.1$ \\
\hline p-value & & & & 0.0004 & & 0.013 & & 0.012 \\
\hline
\end{tabular}




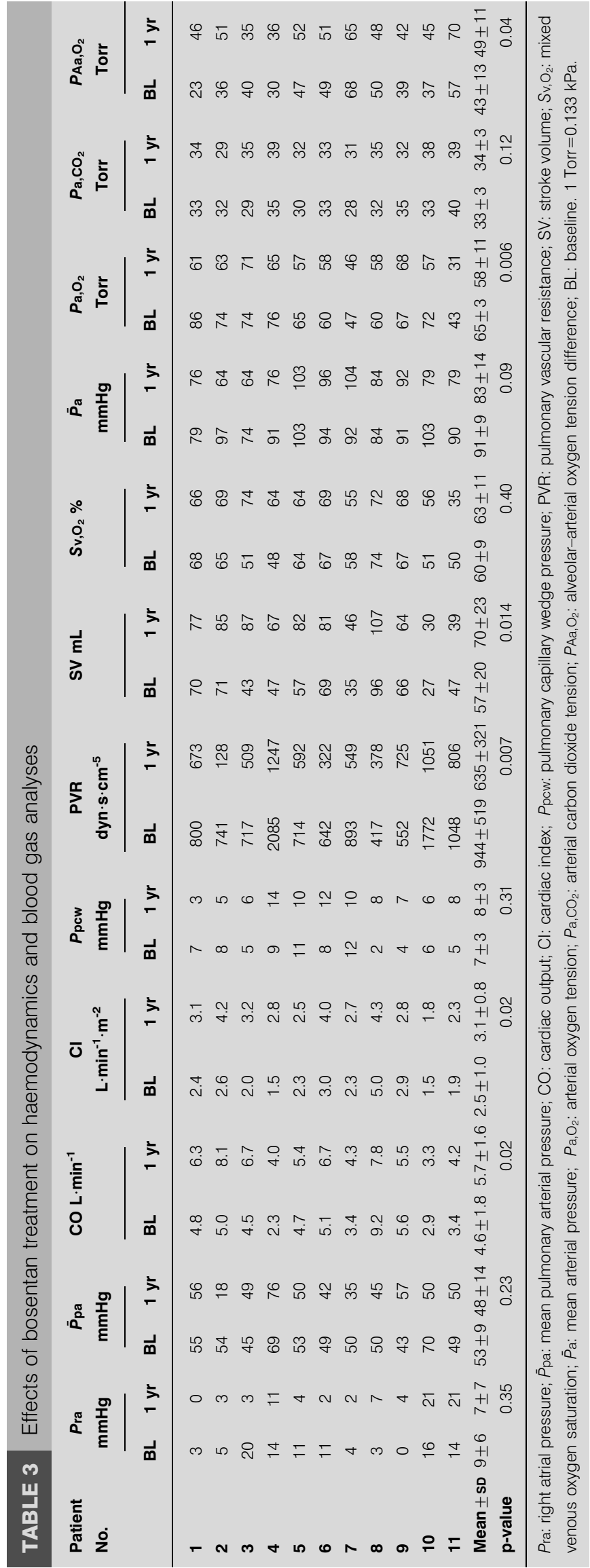

increased from $5.7 \pm 1.7 \mathrm{kPa}(43 \pm 13 \mathrm{mmHg})$ to $6.5 \pm 1.5 \mathrm{kPa}$ $(49 \pm 11 \mathrm{mmHg} ; \mathrm{p}=0.04)$. However, no patient complained of increasing dyspnoea at rest or during exertion.

\section{Side-effects}

Bosentan treatment was well tolerated by all of the patients. Although there was a decline in mean systemic artery pressure, there were no clinical signs or symptoms of hypotension and no episodes of syncope. Most notably, there was no evidence for drug-induced liver toxicity. Hepatic aminotransferase activities were normal or slightly abnormal (less than twice the upper limit of normal) in all patients at baseline and remained practically stable throughout the whole observation period (table 4). The same was true for bilirubin levels, which were $29 \pm 12 \mu \mathrm{mol} \cdot \mathrm{L}^{-1}$ at baseline and $26 \pm$ $10 \mu \mathrm{mol} \cdot \mathrm{L}^{-1}$ after $1 \mathrm{yr}(\mathrm{p}=0.19)$. Parameters of liver synthesis, i.e. international normalised ratio and serum albumin activity levels remained unchanged (table 4). No encephalopathy and no episodes of variceal bleeding were observed. One patient developed increasing amounts of ascites 7 months after the introduction of bosentan. The patients had previously suffered from several episodes of ascites, and clinical judgement was that this complication was due to worsening of portal hypertension rather than causally linked to bosentan treatment.

\section{DISCUSSION}

For many years the only specific drug treatment available for PPHTN has been continuous intravenous epoprostenol [1, 2, 11, 21]. The present data suggest that the dual endothelin receptor antagonist bosentan may offer a safe and effective noninvasive alternative. All patients in the present series suffered from severe pulmonary hypertension at baseline (NYHA Functional Class III or IV; mean 6MWD $310 \mathrm{~m} ; \bar{P}_{\mathrm{pa}}$ $53 \mathrm{mmHg}$; cardiac index (CI) $2.7 \mathrm{~L} \cdot \mathrm{min}^{-1} \cdot \mathrm{m}^{-2}$; pulmonary vascular resistance $944 \mathrm{dyn} \cdot \mathrm{s} \cdot \mathrm{cm}^{-5}$; right atrial pressure $7 \mathrm{mmHg}$; and mixed venous oxygen saturation $60 \%$ ). In an earlier series of 49 patients with PPHTN of similar severity $\left(\bar{P}_{\text {pa }} 59 \mathrm{mmHg}\right.$ and CI $3.3 \mathrm{~L} \cdot \mathrm{min}^{-1} \cdot \mathrm{m}^{-2}$ ), who did not receive specific treatment for pulmonary hypertension, ROBALINO and MoODIE [10] reported a 1-yr mortality of $>60 \%$. Another series of 39 patients with PPHTN from France with comparable haemodynamics $\left(\bar{P}_{\text {pa }} 56 \mathrm{mmHg}\right.$ and CI $\left.2.7 \mathrm{~L} \cdot \mathrm{min}^{-1} \cdot \mathrm{m}^{-2}\right)$ found a 1-yr mortality of $24 \%$ [7]. During the 1-yr observation period reported here, no patient died, which is remarkable given the grave prognosis of this condition. However, the present data do not provide sufficient evidence to conclude that bosentan improves survival in PPHTN.

All patients in the present case series experienced functional improvement, with increasing exercise tolerance; six patients improved by one functional class. The 6MWD increased by a mean of $78 \mathrm{~m}$, and, in those patients who were followed by cardiopulmonary exercise testing, there was a substantial increase in peak oxygen uptake and oxygen pulse, suggesting improved cardiopulmonary function during exercise. In addition, treatment with bosentan improved cardiopulmonary haemodynamics at rest; after 1 yr of bosentan treatment, $\bar{P}_{\text {pa }}$ had fallen by $10 \%$ from baseline, cardiac output had increased by $22 \%$ and pulmonary vascular resistance had fallen by $32 \%$. 


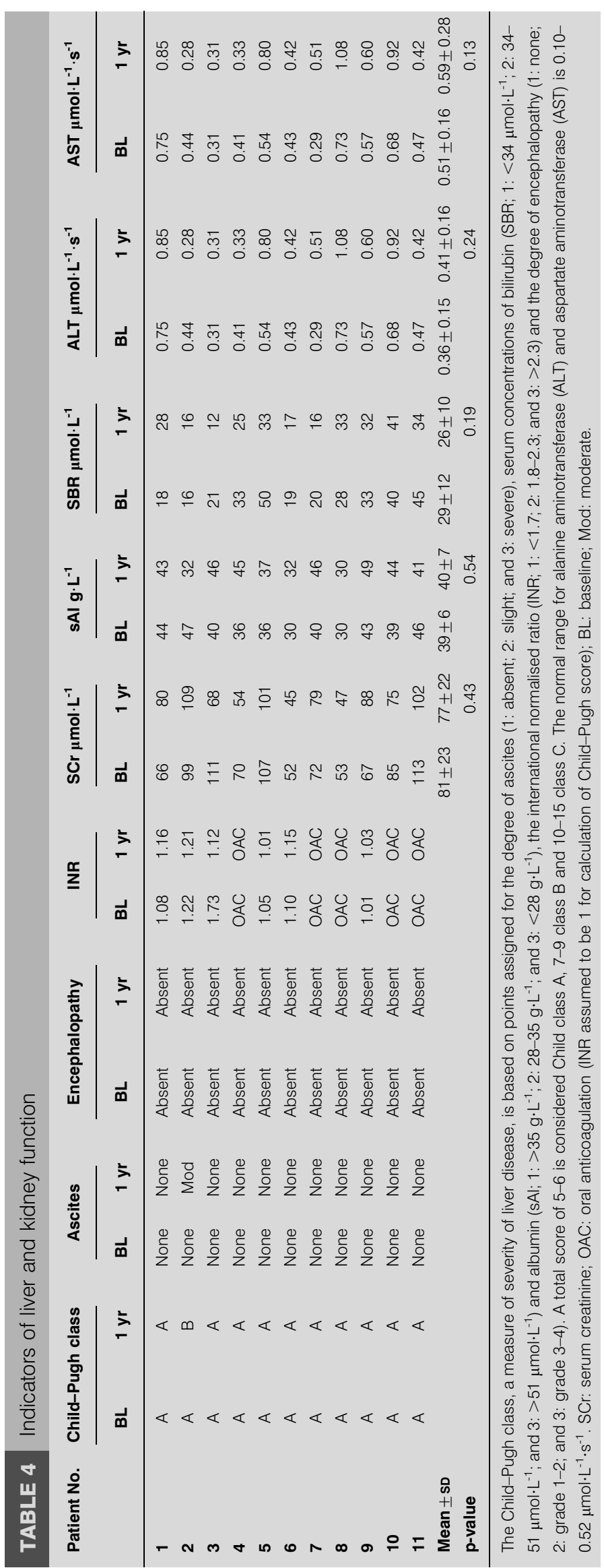

The present data confirm previous studies on the efficacy of bosentan in other forms of PAH [17-19, 22, 23]. Together, these observations support the hypothesis that endothelin is a pathogenetically relevant mediator in pulmonary hypertension of various aetiologies. A recent study found significantly elevated plasma endothelin-1 levels in patients with PPHTN compared to cirrhotic patients with portal hypertension but without pulmonary hypertension [8]. In addition, a large body of evidence suggests that endothelin-1 may also be involved in the pathogenesis of portal hypertension [24-28]. A recent case report of a patient with PPHTN (who was included in the present study) described normalisation of portal venous pressures with bosentan treatment [20]. Thus, the beneficial effects of bosentan in PPHTN could be related to a reduction in both pulmonary and portal hypertension. Unfortunately, no systematic follow-up information exists on portal hypertension in the present patients, but this aspect should be addressed in forthcoming trials.

There are serious safety concerns regarding the administration of bosentan in patients with coexisting liver disease since potential hepatotoxicity is a well-recognised side-effect of bosentan [18]. Presumably, the underlying mechanism is inhibition by bosentan and its metabolites of a bile salt transporter pump [29]. In order to prevent serious liver damage, regulatory agencies demand that hepatic aminotransferase levels be checked every 4 weeks before a new prescription of bosentan is filled. With these precautions in place, there have been no reports of serious or permanent liver damage associated with bosentan. It was hypothesised that the same precautions should prevent drug-related liver toxicity and worsening of liver function in patients with underlying liver disease. To date, this hypothesis seems to be correct, but it is important to note that great caution is still necessary when bosentan is given to patients with liver disease. It must be emphasised that all of the present patients exhibited stable liver function (Child class A). In these patients, it has been shown that metabolism of bosentan is not impaired [30]. In patients with more advanced liver disease, metabolism of bosentan might be impaired, leading to increased plasma concentrations and potentially resulting in enhanced toxicity. Until more data are available, bosentan should probably not be used in patients with more advanced liver dysfunction (Child class B/C).

It is also noteworthy that a trend towards a fall in systemic blood pressure was observed with bosentan in the present PPHTN patients, an observation that has not been made in other populations of PAH patients. Although the decline in systemic blood pressure was not associated with any clinical symptoms in the present patients, it is important to be careful regarding use of bosentan in patients with pre-existing hypotension. The appropriate dosage of bosentan in patients with liver dysfunction should be addressed in forthcoming studies.

Similar considerations apply to potential worsening of arterial oxygenation, since a mild-but-significant fall in $\mathrm{Pa}_{\mathrm{a}} \mathrm{O}_{2}$ was observed in most of the present patients after $1 \mathrm{yr}$ of bosentan treatment. The reason for this finding is unclear, but presumably, worsening of arterial oxygenation may have been caused by nonselective intrapulmonary vasodilation, resulting 
in some degree of ventilation-perfusion mismatching. A fall in $\mathrm{Pa}_{1} \mathrm{O}_{2}$ was also reported with the use of epoprostenol in PPHTN [11], supporting the hypothesis that intrapulmonary vasodilation might be involved in this process.

The limitations of the present study are obvious. The number of patients investigated was small (11 patients treated at three university hospitals) and the study retrospective, patients and investigators were not blinded, and there was no control group. It needs to be emphasised that the presnt report describes all patients with PPHTN who were referred to the three participating centres over a 1-yr period, underscoring the fact that severe PPHTN is truly a rare condition. It is of note that there are also no controlled data on the use of epoprostenol in this condition, and most of the published case series with epoprostenol in PPHTN included even fewer patients $[12,14,15]$, the largest published series consisting of 10 patients [11]. To date, no randomised double-blind controlled clinical trials have ever been performed in PPHTN, but, given the evolving cooperation between pulmonary hypertension centres, such trials might be feasible in the future.

In conclusion, bosentan treatment was found to be safe and effective in the present case series of patients with severe portopulmonary hypertension. If these findings can be confirmed in future trials, bosentan would be the first noninvasive treatment option for this life-threatening disease.

\section{REFERENCES}

1 Rodríguez-Roisin R, Krowka MJ, Hervé Ph, Fallon MB, on behalf of the ERS Task Force Pulmonary-Hepatic Vascular Disorders (PHD) Scientific Committee. Pulmonary-hepatic vascular disorders (PHD). Eur Respir J 2004; 24: 861-880.

2 Hoeper MM, Krowka MJ, Strassburg CP. Portopulmonary hypertension and hepatopulmonary syndrome. Lancet 2004; 363: 1461-1468.

3 McDonnell PJ, Toye PA, Hutchins GM. Primary pulmonary hypertension and cirrhosis: are they related? Am Rev Respir Dis 1983; 127: 437-441.

4 Taura P, Garcia-Valdecasas JC, Beltran J, et al. Moderate primary pulmonary hypertension in patients undergoing liver transplantation. Anesth Analg 1996; 83: 675-680.

5 Hadengue A, Benhayoun MK, Lebrec D, Benhamou JP. Pulmonary hypertension complicating portal hypertension: prevalence and relation to splanchnic hemodynamics. Gastroenterology 1991; 100: 520-528.

6 Castro M, Krowka MJ, Schroeder DR, et al. Frequency and clinical implications of increased pulmonary artery pressures in liver transplant patients. Mayo Clin Proc 1996; 71: 543-551.

7 Herve P, Lebrec D, Brenot F, et al. Pulmonary vascular disorders in portal hypertension. Eur Respir J 1998; 11: 1153-1166.

8 Benjaminov FS, Prentice M, Sniderman KW, Siu S, Liu P, Wong F. Portopulmonary hypertension in decompensated cirrhosis with refractory ascites. Gut 2003; 52: 1355-1362.

9 Plevak D, Krowka M, Rettke S, Dunn W, Southorn P. Successful liver transplantation in patients with mild to moderate pulmonary hypertension. Transplant Proc 1993; 25: 1840 .
10 Robalino BD, Moodie DS. Association between primary pulmonary hypertension and portal hypertension: analysis of its pathophysiology and clinical, laboratory and hemodynamic manifestations. J Am Coll Cardiol 1991; 17: 492-498.

11 Krowka MJ, Frantz RP, McGoon MD, Severson C, Plevak DJ, Wiesner RH. Improvement in pulmonary hemodynamics during intravenous epoprostenol (prostacyclin): a study of 15 patients with moderate to severe portopulmonary hypertension. Hepatology 1999; 30: 641648.

12 Kuo PC, Johnson LB, Plotkin JS, Howell CD, Bartlett ST, Rubin LJ. Continuous intravenous infusion of epoprostenol for the treatment of portopulmonary hypertension. Transplantation 1997; 63: 604-606.

13 Kuo PC, Plotkin JS, Gaine SP, et al. Portopulmonary hypertension and the liver transplant candidate. Transplantation 1999; 67: 1087-1093.

14 Plotkin JS, Kuo PC, Rubin LJ, et al. Successful use of chronic epoprostenol as a bridge to liver transplantation in severe portopulmonary hypertension. Transplantation 1998; 65: 457-459.

15 McLaughlin VV, Genthner DE, Panella MM, Hess DM, Rich S. Compassionate use of continuous prostacyclin in the management of secondary pulmonary hypertension: a case series. Ann Intern Med 1999; 130: 740-743.

16 Swanson KL, McGoon MD, Krowka MJ. Survival in patients with portopulmonary hypertension. Am J Respir Crit Care Med 2003; 167: A693.

17 Channick RN, Simonneau G, Sitbon O, et al. Effects of the dual endothelin-receptor antagonist bosentan in patients with pulmonary hypertension: a randomised placebocontrolled study. Lancet 2001; 358: 1119-1123.

18 Rubin LJ, Badesch DB, Barst RJ, et al. Bosentan therapy for pulmonary arterial hypertension. N Engl J Med 2002; 346: 896-903.

19 Hoeper MM, Taha N, Bekjarova A, Gatzke R, Spiekerkoetter E. Bosentan treatment in patients with primary pulmonary hypertension receiving nonparenteral prostanoids. Eur Respir J 2003; 22: 330-334.

20 Halank M, Miehlke S, Hoeffken G, Schmeisser A, Schulze M, Strasser RH. Use of oral endothelinreceptor antagonist bosentan in the treatment of portopulmonary hypertension. Transplantation 2004; 77: 17751776.

21 Naeije R. Hepatopulmonary syndrome and portopulmonary hypertension. Swiss Med Wkly 2003; 133: 163169.

22 Barst RJ, Ivy D, Dingemanse J, et al. Pharmacokinetics, safety, and efficacy of bosentan in pediatric patients with pulmonary arterial hypertension. Clin Pharmacol Ther 2003; 73: 372-382.

23 Williamson DJ, Wallman LL, Jones R, et al. Hemodynamic effects of bosentan, an endothelin receptor antagonist, in patients with pulmonary hypertension. Circulation 2000; 102: 411-418.

24 Chan CC, Wang SS, Lee FY, et al. Endothelin-1 induces vasoconstriction on portal-systemic collaterals of portal hypertensive rats. Hepatology 2001; 33: 816-820.

25 Bakr AM, Abdalla AF, El-Marsafawy $\mathrm{H}$, et al. Plasma endothelin-1 concentrations in children with cirrhosis and 
their relationship to renal function and the severity of portal hypertension. J Pediatr Gastroenterol Nutr 2002; 35: 149-153.

26 Chongsrisawat V, Chatchatee P, Samransamruajkit R, Vanapongtipagorn $\mathrm{P}$, Chottivittayatarakorn $\mathrm{P}$, Poovorawan Y. Plasma endothelin-1 levels in patients with biliary atresia: possible role in development of portal hypertension. Pediatr Surg Int 2003; 19: 478-481.

27 Kojima H, Sakurai S, Kuriyama S, et al. Endothelin-1 plays a major role in portal hypertension of biliary cirrhotic rats through endothelin receptor subtype B together with subtype A in vivo. J Hepatol 2001; 34: 805-811.
28 Tieche S, De Gottardi A, Kappeler A, et al. Overexpression of endothelin-1 in bile duct ligated rats: correlation with activation of hepatic stellate cells and portal pressure. J Hepatol 2001; 34: 38-45.

29 Fattinger K, Funk C, Pantze M, et al. The endothelin antagonist bosentan inhibits the canalicular bile salt export pump: a potential mechanism for hepatic adverse reactions. Clin Pharmacol Ther 2001; 69: 223-231.

30 van Giersbergen PL, Popescu G, Bodin F, Dingemanse J. Influence of mild liver impairment on the pharmacokinetics and metabolism of bosentan, a dual endothelin receptor antagonist. J Clin Pharmacol 2003; 43: 15-22. 